Proceedings

\title{
Health state valuation and its socio-economic factors: online samples from the U.S. and Canada
}

\author{
Liang Wang
}

Publisher's Note: MDPI stays neutral with regard to jurisdictional

claims in published maps and institutional affiliations.

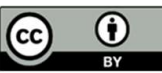

Copyright: (C) 2020 by the authors. Submitted for possible open access publication under the terms and conditions of the Creative Commons Attribution (CC BY) license (http://creativecommons.org/licenses/by/4.0/).

\author{
Department of Economics, Concordia University, 1455 de Maisonneuve Blvd. West, Room H 1155, Mon- \\ treal, Quebec H3G 1M8, Canada \\ * Correspondence: lia_wa@live.concordia.com
}

\begin{abstract}
This paper seeks to explore how people value the state of health and what socio-economic factors they might consider. I conducted an online experiment and a survey to elicit individuals' decisions under hypothetical health states, which vary at three levels: mild, moderate, and severe. The socio-economic factors mainly include payment, personal financial situation, hospital service, support from the family, etc. The subjects were from two separate online pools of the United States and Canada, which have similar socio-economic backgrounds and different health care systems. This paper presents that subjects are sensitive to different levels of health states. In those who choose the risky medical treatment under the same health states, the Canadian participants are willing to accept a lower success probability. Among the socio-economic factors that are significant to this health-related decision, some factors are only significant in one country's participants. For the American sample, it is "access to health insurance", while for the Canadian sample, it is "disturbances in everyday family life".
\end{abstract}

Keywords: Health state valuation; Socio-economic factors; Online survey

\section{Introduction}

The fundamental purpose of a health service is to enhance the quality of life by maintaining or improving one's health status. Medical treatments can achieve great improvements in people's health but may also cause negative consequences. When patients choose between remaining in ill-health and taking a risky treatment, they may consider different key factors. Patients may face the risk of failure of treatment and/or the financial cost of receiving the treatment. Even under publicly funded health care for which patients will not need to make the payment out of their pockets, they still have to consider other factors such as the income deduction, the disturbance of daily life, and the support of the family. This paper aims to explore the socio-economic elements that people may consider when valuing the state of ill-health.

\section{Methods}

\subsection{Health State Valuation}

The term "health state" used in this project is originally rooted in the concept of the quality-adjusted life-year (QALY) in Health Economics, which defines the desirability of a health state based on how an individual would value being in that health state herself or himself. Individual decisions are governed by individual ex-ante preferences [4].

The dimensions of health state used in this paper are based on the SF-6D, which was a six-dimensional health state classification (Brazier, Usherwood, Harper, \& Thomas, 1998) [1]. The six dimensions that are in order are physical functioning, role limitations, social functioning, pain, mental health, and vitality. Each of the six digits of the health state indicates the level on each dimension of the SF-6D. Among the reported 24 health states, I filter three health states which are considered as mild, moderate, and severe 
(Health State A 111212, Health State B 422413, and Health State C 625655). All three health states were presented to the participants one after the other, each in a pre-determined order designed for randomness. After being notified of one health state, the subjects valued this health state in a modified Health States Standard Gamble (SG). They decided whether or not they would take this risky treatment to improve their health and what probability of success they will accept in the outcome of the treatment table. In this valuation, the success probability $\mathrm{P}$ which is accepted by the subject is called the standard gamble value (SG value hereafter).

\subsection{Socio-Economic Questionnaire}

The second part of the experiment is the questionnaire, which examines participants' healthcare background, payment methods, and other socio-economic factors.

Based on the fact that participants are from the United States and Canada, this paper categorizes the medical payment into three groups: the public, the private, and the uninsured [4]. In the survey, in the private group is specified as employer-purchase and personal-purchase.

\subsection{Research Questions}

There are three steps in the whole experiment. The "Preface" questions are purposely placed before the SG during step 1, serving as a "refreshment" for the participants" memory of their medical experiences. In step 2, the participants were given a standard gamble for each of the three health states. The "Follow-up" questionnaire is done right after step 2 and explores the socio-economic factors.

This paper aims to answer the following questions:

1. Will participants in both countries distinguish between the three health states and make corresponding decisions in each state?

2. Will decisions on the health state standard gamble vary between the two countries? Is this difference consistent across all health states?

3. Are there any common components of the payment system and socio-economic factors involved in a healthy state's valuation? Are these components consistent across the three health states in each nation?

4. How will these common components affect health-related decisions, and to what extent will the two countries vary in their respective features?

\subsection{Experimental procedure}

I designed the experiment for the two countries and coded the United States version with oTree [2]. The samples from the two countries were collected from two separate platforms. The U.S. version was conducted on the online labor force platform Amazon Mechanical Turk (MTurk). For the Canadian version, the researcher cooperated with the third party AskCanadians. AskCanadians' posting period is 24 March 2020-30 March and MTurk's posting period is 27 March 2020-02 April.

\section{Results}

\subsection{Summary of Demographic Information}

There are 200 participants from each country. The Canadian sample covers all ten provinces, and the four largest proportions of participants are from Ontario, Quebec, British Columbia, and Alberta. The American participants come from 38 states. The Kolmogorov-Smirnov test shows that there is no significant difference in the income distribution between the two countries (one tail $p=0.299$ ). The highest percentage in the American sample is $23 \%$, for the category of $\$ 75,000$ to $\$ 99,999$; while the highest proportion in the Canadian sample is $24 \%$, for the category of $\$ 100,000$ or greater. The Kolmogorov-Smirnov test shows that the Canadian participants are significantly younger than the American participants (one tail $p=0.000$ ). The highest percentage in the Canadian sample is $48.5 \%$, which is the age group of 25-34; while the highest percentage in the American sample is 
$20 \%$, which is the age group of $45-54$. One Canadian participant selected "Other" in gender; besides that, there are $52 \%$ female in the Canadian sample and $43.5 \%$ female in the American sample.

\subsection{Findings}

\subsubsection{Finding 1: (Comparison across health states)}

When the health state worsens, the participants are willing to accept a risky medical treatment with a lower probability of success. This finding holds for both samples.

The paired t-tests (see Table 1) generally support the results found in the statistical summary. The SG value decreases as the health state deteriorates. All comparisons between the three health states are significant for the Canadian participants. For American participants, however, this difference between SG1 and SG2 does not appear to be significant. As a robust check, the tests are also done with the data excluding the SG=0 and violate monotonicity. Compared to the original data, the excluding data shows SG1 >SG2 is significant in the USA.

Table 1. Paired t-test on the SG values between the three states.

\begin{tabular}{|c|c|c|c|}
\hline \multicolumn{4}{|c|}{ The Paired Two-Tailed t-Test of the American Sample } \\
\hline Hypothesis (H0) & SG1=SG2 & SG2 $=$ SG3 & SG1= SG3 \\
\hline $\operatorname{Pr}(|\mathrm{T}|>|\mathrm{t}|)$ & 0.1237 & $0.0012^{* * *}$ & $0.0007^{* * *}$ \\
\hline [95\% Conf. Interval of diff] & {$[-0.86,7.07]$} & {$[3.00,12.00]$} & {$[4.32,15.71]$} \\
\hline Paired obs. & 161 & 173 & 163 \\
\hline Result (H1) & SG1> SG2 & SG2> SG3 & SG1> SG3 \\
\hline \multicolumn{4}{|c|}{ The Paired Two-Tailed t-Test of the Canadian Sample } \\
\hline Hypothesis (H0) & SG1= SG2 & SG2= SG3 & SG1=SG3 \\
\hline $\operatorname{Pr}(|T|>|t|)$ & $0.0010^{* * *}$ & $0.0000^{* * *}$ & $0.0000^{* * *}$ \\
\hline [95\% Conf. Interval of diff] & {$[2.99,11.52]$} & {$[11.77,20.84]$} & {$[14.85,27.13]$} \\
\hline Paired obs. & 151 & 168 & 151 \\
\hline Result (H1) & SG1> SG2 & $\mathrm{SG} 2>\mathrm{SG} 3$ & SG1> SG3 \\
\hline
\end{tabular}

${ }^{* * *} p<0.01,{ }^{* *} p<0.05,{ }^{*} p<0.1$.

\subsubsection{Finding 2: (Comparison across samples)}

More Canadian participants choose "No-Treatment" than American participants in all three health states. Conditional on choosing "Treatment", the American participants significantly have higher SG values than Canadian participants, regardless of the health state they were given.

The box plot (see Figure 1) shows the SG value distribution of the two-group participants. Comparing the box by countries, the boxes of Canadian samples are lower than those of American samples in moderate and severe health states. This conclusion is supported by the results shown in Table 2. The t-test shows that for all health states, the SG value in American samples is higher than Canadian's, which is all statistically significant at the $95 \%$ confidence level. 


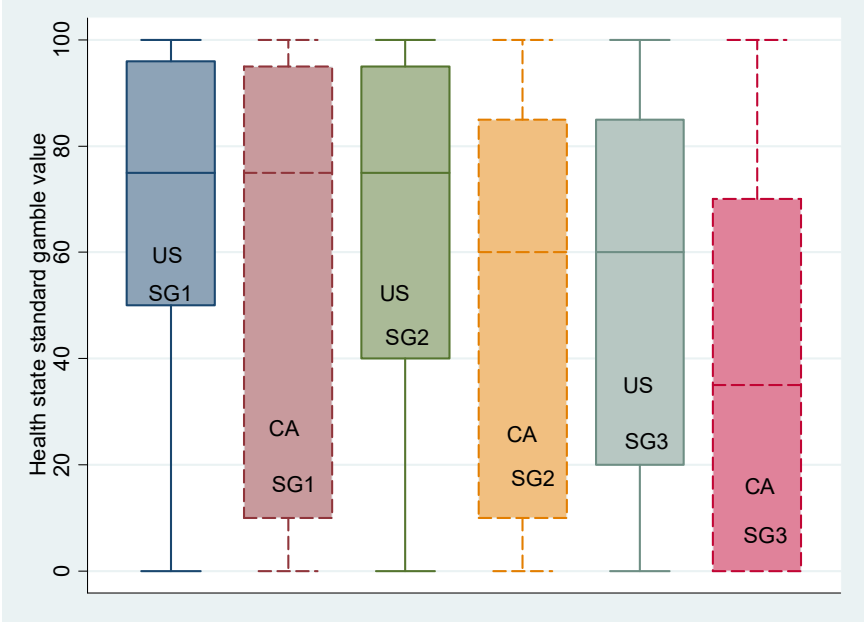

Figure 1. Box plot for health state standard gamble (SG) value (Conditional on choosing Option B). US: United States sample. CA: Canadian sample.

Table 2. Paired two-tailed t-test on SG value between the two samples.

\begin{tabular}{cccc}
\hline & Health State 1 & Health State 2 & Health State 3 \\
\hline Hypothesis $(\mathrm{H} 0)$ & USA $=$ CA & USA $=$ CA & USA=CA \\
$\operatorname{Pr}(|\mathrm{T}|>|\mathrm{t}|)$ & $0.0371^{* *}$ & $0.0013^{* * *}$ & $0.00000^{* * *}$ \\
{$[95 \%$ Conf. Interval of diff] } & {$[-0.70,15.03]$} & {$[4.06,19.09]$} & {$[10.50,24.58]$} \\
Combined obs. & 326 & 355 & 371 \\
Result $(\mathrm{H} 1)$ & $\mathrm{USA}>\mathrm{CA}$ & $\mathrm{USA}>\mathrm{CA}$ & $\mathrm{USA}>\mathrm{CA}$ \\
\hline
\end{tabular}

${ }^{* * *} p<0.01,{ }^{* *} p<0.05,{ }^{*} p<0.1$.

\subsubsection{Finding 3: (Comparison in PCA)}

Between the two countries' samples, the principal component analysis (PCA) components in the "Source of medical payment" are the same, but the PCA components in the "Personal factor" category are not identical

This paper applies the principal component analysis (PCA) to the original factors reported in the questionnaire (see Table 3). Unlike the original separate factors, the scores of the components are not correlated. Each component is renamed as a meaningful variable.

Table 3. PCA components.

\begin{tabular}{cc}
\hline American Sample Category A & Source of Medical Payment \\
\hline Payment Factor-Individual & $\begin{array}{c}\text { Self-purchased insurance plans } \\
\text { Out-of-pocket payments }\end{array}$ \\
\hline Payment Factor-Government & Government-provided health-insurance \\
\hline Payment Factor-Employment & Employer (current, former)-purchased insurance plans \\
\hline Cumulative & 0.8477 \\
\hline Kaiser-Meyer-Olkin & 0.5446 \\
\hline American Sample Category B & Personal Factor \\
\hline Personal Factor-Financial & Access to health insurance \\
& Personal financial situation \\
\hline Personal Factor-Service \&Support & Waiting time for the treatment \\
& Service of hospitals \\
\hline Personal Factor-Daily Life & Support from the family or friends \\
\hline Cumulative & Disturbances in everyday family life \\
\hline Kaiser-Meyer-Olkin & 0.7415 \\
\hline Canadian Sample Category A & 0.7227 \\
\hline
\end{tabular}




\begin{tabular}{cc} 
Payment Factor-Individual & $\begin{array}{c}\text { Self-purchased insurance plans } \\
\text { Out-of-pocket payments }\end{array}$ \\
\hline Payment Factor-Government & Government-provided health-insurance \\
\hline Payment Factor-Employment & Employer (current, former)-purchased insurance plans \\
\hline Cumulative & 0.8266 \\
\hline Kaiser-Meyer-Olkin & 0.5231 \\
\hline Canadian Sample Category B & Personal Factor \\
Personal Factor-Service \&Financial & Waiting time for the treatment \\
& Service of hospitals \\
Personal financial situation
\end{tabular}

\subsubsection{Finding 4: (Comparison across samples)}

In the health state valuation, many factors are significant in both countries' participants such as "employer-purchased insurance plans", "waiting time for the treatment", and "personal financial situation". But the two counties' participants also show different considered factors. For the American sample, it is "access to health insurance", while for the Canadian sample, it is "disturbances in everyday family life".

By regressing the SG value with PCA factor scores, this paper shows which factors may be associated with health state valuation (see Table 4). After tracing the PCA factors back to the original factors in the survey, I summarize the factors in Table 5.

Table 4. Tobit regression of SG value and factors in the two samples.

\begin{tabular}{|c|c|c|c|}
\hline USA SG Value & & CA SG Value & \\
\hline Health State & $\begin{array}{l}-0.195 \\
(-0.165)\end{array}$ & Health State & $\begin{array}{l}-0.340^{* * *} \\
(-0.0825)\end{array}$ \\
\hline Gender & $\begin{array}{c}-8.563^{* * *} \\
(-1.152)\end{array}$ & Gender & $\begin{array}{c}-9.525^{* * *} \\
(-0.756)\end{array}$ \\
\hline Age & $\begin{array}{l}-1.241^{* * *} \\
(-0.344)\end{array}$ & Age & $\begin{array}{l}-2.205^{* * *} \\
(-0.196)\end{array}$ \\
\hline Income & $\begin{array}{l}-0.432 \\
(-0.287)\end{array}$ & Income & $\begin{array}{c}-1.685^{* * *} \\
(-0.163)\end{array}$ \\
\hline Lack & $\begin{array}{l}-7.104^{* * *} \\
(-0.942)\end{array}$ & Lack & $\begin{array}{c}-3.486^{* * *} \\
(-0.46)\end{array}$ \\
\hline Payment Factor-Individual & $\begin{array}{c}0.273 \\
(-0.629)\end{array}$ & Payment Factor-Individual & $\begin{array}{l}-1.598^{* * *} \\
(-0.225)\end{array}$ \\
\hline $\begin{array}{c}\text { Payment Factor-Govern- } \\
\text { ment }\end{array}$ & $\begin{array}{c}0.637 \\
(-0.501)\end{array}$ & $\begin{array}{c}\text { Payment Factor-Govern- } \\
\text { ment }\end{array}$ & $\begin{array}{l}1.952^{* * *} \\
(-0.222)\end{array}$ \\
\hline $\begin{array}{l}\text { Payment Factor-Employ- } \\
\text { ment }\end{array}$ & $\begin{array}{l}1.047^{*} \\
(-0.634)\end{array}$ & $\begin{array}{l}\text { Payment Factor-Employ- } \\
\text { ment }\end{array}$ & $\begin{array}{l}0.696^{* * *} \\
(-0.269)\end{array}$ \\
\hline Personal Factor-Financial & $\begin{array}{l}-1.246^{* * *} \\
(-0.453)\end{array}$ & $\begin{array}{c}\text { Personal Factor-Service } \\
\text { \&Financial }\end{array}$ & $\begin{array}{l}-1.917^{* * *} \\
(-0.142)\end{array}$ \\
\hline $\begin{array}{c}\text { Personal Factor-Service } \\
\text { \&Support }\end{array}$ & $\begin{array}{l}0.915^{*} \\
(-0.543)\end{array}$ & Personal Factor-Family & $\begin{array}{l}1.090^{* * *} \\
(-0.332)\end{array}$ \\
\hline Personal Factor-Daily Life & $\begin{array}{l}-0.0171 \\
(-0.529)\end{array}$ & Personal Factor-Insurance & $\begin{array}{c}0.359 \\
(-0.435)\end{array}$ \\
\hline Constant & $\begin{array}{l}55.27^{* * *} \\
(-1.738)\end{array}$ & Constant & $\begin{array}{l}53.86^{* * *} \\
(-0.834)\end{array}$ \\
\hline
\end{tabular}




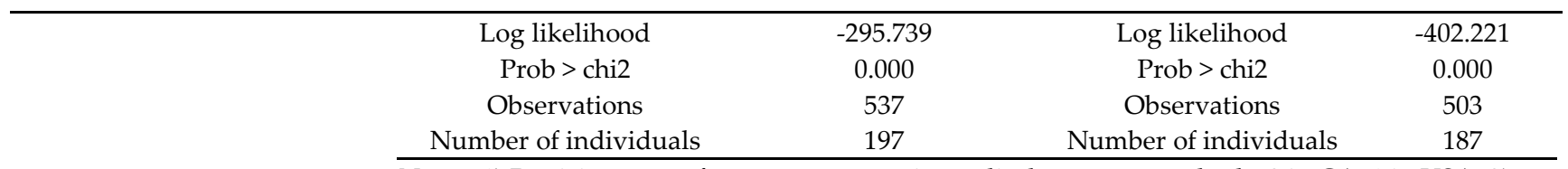

Notes: 1) Participants prefers not to answer in medical payment methods: 3 in CA; 1 in USA; 2) Participants chose "Non-Treatment" in all three health states: 10 in CA and 2 in USA 3) Standard errors in parentheses, ${ }^{* *} p<0.01,{ }^{* *} p<0.05,{ }^{*} p<0.1$.

Table 5. Summary of the significant factors from the Tobit regression.

\begin{tabular}{|c|c|c|c|c|}
\hline & & America & & Canada \\
\hline Source of medical payments & plans & employer-purchased insurance & $\begin{array}{l} \\
\bullet \\
\bullet \\
\bullet \\
\text { ance }\end{array}$ & $\begin{array}{ll}\text { - } & \text { employer-purchased insurance plans } \\
\text { - } & \text { self-purchased insurance plans } \\
\text { - } & \text { out-of-pocket payments } \\
\text { government-provided health-insur- }\end{array}$ \\
\hline $\begin{array}{c}\text { Personally considered fac- } \\
\text { tors }\end{array}$ & $\begin{array}{l} \\
\bullet \\
\bullet \\
\bullet \\
\bullet\end{array}$ & $\begin{array}{l}\text { - } \\
\text { waiting time for the treatment } \\
\text { - } \\
\text { - } \\
\text { - } \\
\text { - } \\
\text { supervice of hospitals } \\
\text { access to health insurance }\end{array}$ & $\begin{array}{l} \\
\bullet \\
\bullet \\
\bullet \\
\bullet\end{array}$ & $\begin{array}{l}\text { - } \\
\text { - } \\
\text { service of hospitals } \\
\text { - } \\
\text { - } \\
\text { - } \\
\text { supporsonal financial situation } \\
\text { disturbances in everyday family life }\end{array}$ \\
\hline Exogenous variables & $\begin{array}{l}\bullet \\
\bullet \\
\bullet\end{array}$ & $\begin{array}{ll}\text { - } & \text { gender } \\
\text { - } & \text { age } \\
\text { - } & \text { lack }\end{array}$ & $\begin{array}{l}\bullet \\
\bullet \\
\bullet \\
\bullet \\
\bullet\end{array}$ & $\begin{array}{ll} & \text { gender } \\
- & \text { age } \\
- & \text { lack } \\
- & \text { health state } \\
- & \text { income }\end{array}$ \\
\hline
\end{tabular}

Notes: The factors in bold are significant in both American and Canadian samples.

\section{Discussion}

For future research, larger sample sizes may be considered for comparative studies in these two countries. This paper has a sample size of 200 participants for each country. Most of the results could have wider implications with larger sample sizes. In the survey, subjects make decisions based on a hypothetical health state that is designed to be comparable and measurable between different people. However, a person's actual health status could be an interesting variable that could be added to the experiment.

\section{Conclusions}

From an individual's view, health-related decisions may be associated with multiple socio-economic factors. This paper explores these decisions and factors through a survey experiment based on two online samples.

Acknowledgments: The author would like to thank all those who participated in this study, particularly Prof. Huan Xie from Concordia University, and Prof. Thomas G. Poder from the University of Montreal.

Conflicts of Interest: Author identifies and declares no personal circumstances or interest that may be perceived as inappropriately influencing the representation or interpretation of reported research results.

\section{References}

1. Brazier, J., Usherwood, T., Harper, R., \& Thomas, K. (1998). Deriving a preference based single index measure from the SF-36. Journal of Clinical Epidemiology. volume 51, issue 11, 1115-1128.

2. Chen, D. L., Schonger, M., \& Wickens, C. (2016). oTree - An open-source platform for laboratory, online and field experiments. J. of Behavioral and Experimental Finance. 9(1), 88-97. 
3. Miller, E., Banthin, J. S., \& Moeller, J. F. (2004). Covering the Uninsured: Estimates of the Impact on Total Health Expenditures for 2002. Agency for Healthcare Research and Quality Working Paper No. 04007, http://www.ahrq.gov.

4. Weinstein, M. C., Torrance, G., \& McGuire , A. (2009). QALYs: The Basics. Value in Health. Volume12, Issues1, S5-S9. 